\title{
Effectiveness of TIMSS Requirements-based Professional Learning Community in Developing Pedagogical Content Knowledge among Science Teachers
}

\author{
Eman M. ALRwaythi \\ Associate Professor of Science Education, \\ Imam Muhammad ibn Saud Islamic University, \\ Saudi Arabia

\section{Reem T. AL-Otaibi} \\ Ph. D, Teaching Methodology, \\ Imam Muhammad ibn Saud Islamic University, \\ Saudi Arabia
}

Doi: 10.36941/jesr-2020-0024

\begin{abstract}
The current study aims to build a Professional Learning Community (PLC) based on the requirements of the Trends in International Mathematics and Science Study (TIMSS) and to develop Pedagogical Content Knowledge (PCK) among female Science teachers of middle school. The quasi-experimental approach was adopted and applied to a sample of (20) female Science teachers selected from middle schools in Riyadh, Saudi Arabia. The PCK scale, PLC focus groups, and self-reflection sessions were utilized. The study results demonstrated that the PLC based on TIMSS requirements is effective in the development of PCK among participants. It helped improve their abilities to reflect on the teaching methods and techniques they employ and to focus on and identify their professional development needs. PLC sessions met some of these needs, including training on designing reflective activities, composing good descriptive questions appropriate to TIMSS learning levels, as well as creating and applying effective PLCs. The study recommends creating PLCS within schools and educational districts and encouraging self-refection and collaborative learning among Science teachers.
\end{abstract}

Keywords: Professional learning community, pedagogical content knowledge, TIMSS, Science, middle school teacher

\section{Introduction}

Science education is getting global attention and importance due to the unprecedented progress witnessed today in all fields of science and its expanded applications in various areas of life. Some countries relate students' success in Math and Science to their economic competiveness. Science education development aims to prepare the individual to be capable of dealing with the rapid changes and the incredible information advancement by encouraging creativity and innovation. Therefore, global systems and ministries of education have sought to develop Science education and to determine its fundamental conceptions and requirements by diagnosing its reality using 
standardized tools and international experiences. International assessments are credible scientific tools designed to evaluate the reality of education. As witnessed in the politics of educational development in international organizations, these assessments form the trends of education and evaluation. The results of TIMSS, for instance, are among the significant inputs of the development and update of the curricula of Science and Mathematics, as well as the preparation of professional development programs for teachers (Ministry of Education, 2019).

TIMSS or Trends in International Math and Science Study is one of the well-known international studies in the fields of Mathematics and Science. It is intended to compare student achievements in Math and Science in different educational systems with varied cultural, economic, and social contexts. It thus aims to identify the level of student achievement in these systems, and to evaluate the impact of the relevant factors affecting student achievement in a specific time (AlHussan, 2015).

The teacher plays an integral role in student learning and understanding of the concepts and knowledge contained in the textbooks. Accordingly, s/he carries the responsibility of understanding the scientific content and presenting it in a way that suits students' learning, which is known as Pedagogical Content Knowledge (PCK). It is "a central feature of the knowledge base of teaching" and it requires a "depth of understanding of the structures of the subject matter knowledge" (Shulman, 1987, p. 9). It also lays an emphasis on the teacher's attitude towards the subject matter and the methods of presenting and transforming it into understandable lessons. According to Shulman (1987, p. 11), PCK has a significant importance because it represents the maxims of "content-specific" knowledge and "general teaching principles" that "guide the practices of able teachers", including the practices of conceptual organization, inquiry, and adaptation. Thus, PCK is a complementary process that can be developed by everyday classroom practices (Thompson et al., 2019). The improvement of teachers' PCK depends on experience, lesson planning, and classroom teaching practices. The main sources of teacher knowledge base include general content-specific knowledge, attitudes, pedagogical knowledge, educational objectives and context, as well as learning resources (Hashweh, 2005). Teachers take the decisions of lesson planning and implementation based on the PCK they got, and thus these decisions indicate their level of PCK development (Drechsler \& Driel, 2008).

Educational studies, such as Hashweh (2005) and Ghoneim, Abd, and Ayyash (2016) concluded that teacher PCK positively affects student academic achievement and motivation towards learning. Kapyla, Heikkinen, and Asunta (2009) demonstrated that scientific content-specific knowledge are the challenges faced by teachers in identifying the concepts difficult for students and determining the main elements of the lesson. Hussein (2014) showed that there is a low level of PCK application among Science teachers even those who are academically and pedagogically qualified.

The study of PCK helps identify the varied teaching methods employed by teachers, strengths and weaknesses of these methods, as well as PCK development techniques. Scholars and educators have explored the elements of PCK among Science teachers. Melo-Niño, Cañada, and Mellado (2017) sought to identify PCK among student teachers during their practicum in Colombian universities. They concluded that PCK was represented in the participants' interpretation of the subjects of Physics courses in their schools, the horizontal correlation between the topics of Physics and Mathematics, the strategies that they believe in their effective in teaching Physics and the time available to teach those subjects. The teacher's deep PCK is a basic characteristic of the successful educational process, i.e. the quality of education varies according to the development of contentspecific knowledge among teachers (Ghoneim, Abd, \& Ayyash, 2016). PCK development depends on two elements. The first is teacher professional development through the training courses attended and the second element is the teacher's attitude towards the subject matter. Accordingly, the teacher evaluates various teaching methods in order to select a set of techniques that help achieve the aspired learning outcomes (Ozden, 2008).

The middle school demands on teachers who possess both knowledge of varied content topics and teaching strategies appropriate for these topics. Scholars and educators have shown interest in studying teachers' knowledge, attitudes, and PCK because they represent a key element of 
interpreting and evaluating their classroom behaviors and their impacts on students' learning (De Jong, Van Driel, \& Verloop, 2005). It also helps prepare effective programs for pre- and in-service teacher education and development.

PLC is a modern technique of professional development emerged in the last decade of the twentieth century (Leclerc, Moreau, Dumouchel, \& Salla, 2012). According to Blitz (2013, p. 3), PLCs are "teams of educators who get together regularly to exchange ideas" that have emerged to "meet school districts' growing interest in promoting professional development that engages teachers and administrators". Members from the same area of interest participate in these communities and engage in activities, discussions, information exchange, and cooperative activities (Wenger, McDermott, \& Snyder, 2002). PLCs assume that peer collaboration improves teaching practices and raises the level of academic achievement among students (Riveros, Newton, \& Burgess, 2012). They are based on the social theory of learning, i.e. teachers share knowledge and build their profession through situated learning within communities of professional practice. It thus creates a vital link between learning and practice. As highlighted by Blitz (2013), teachers who are selfmotivated to participate and learn in PLCs can always acquire new knowledge and apply it within their classrooms.

DuFour (2004) identified a set of PLC principles, including focus on student learning, building a culture of cooperation and interaction among teachers, student achievement improve, shared values, and reflective dialogue. Reflective activities done by teachers include action research, study groups, observation, teaching, and creating an environment supportive for professional development (Owen, 2014; Pratt, 2014).

Many conferences and seminars called for benefiting from PLCs in developing PCK among teachers. The conference of Future Teacher: Preparation and Development, held at King Saud University in the period from 6-7 October 2015, recommended improving teacher education and professional development by initiatives and purposeful tracks. Further, the conference of Teacher Education and Training in the Modern Age, held at Umm Al-Qura University in the period from 2-4 February 2016, highlighted the significance of boosting teacher knowledge, teaching competency, and attitudes. It also emphasized the role played by PLCs in increasing teacher awareness of the future challenges of education. The nineteenth educational supervision forum recommended activating PLCs in schools and educational districts.

Through the researchers' experience in the educational filed, it is evident for them that Science teachers face a difficulty in understanding the dimensions of the general framework of the TIMSS. They also have inadequate knowledge about the main skills that students should acquire based on the requirements of the TIMSS. After interviewing a number of supervisors of Science teachers of middle school, the researchers concluded that teachers do not have enough knowledge about the TIMSS requirements and they do not realize the importance of their continuous professional development. Therefore, the current study aims to evaluate the effectiveness of a PLC based on TIMSS requirements in developing PCK among Science teachers of middle school. It seeks to answer the question of "what is the effectiveness of a PLC based on TIMSS requirements in the development of PCK among Science teachers of middle school?

\section{$1.1 \quad$ Hypothesis}

There are statistically significant differences at the significance level (o.ol) between the mean scores of the experimental group of Science teachers of middle school in the pre and post PCK test, in favor of the post-test mean scores.

\subsection{Objectives}

The current study seeks to build a PLC to develop PCK in the light of the requirements of the TIMSS among female Science teachers of middle school. 


\subsection{Significance}

The current study is significantly relevant to the accomplishment of the indicator of the development of curricula and methods of teaching and evaluation adopted by the Saudi Ministry of Education. It also represents an implication for one of the strategic goals of the Saudi Vision 2030, positive attitudes enhancement and citizen empowerment to build the nation and provide citizens with the knowledge and skills that meet the labor market requirements. The development of PCK increases the performance of effective professional practices among teachers. It also helps meet the aspired learning outcomes, since content-specific knowledge is an essential field of activity of the Saudi professional standards for teachers. Science teachers and supervisors are called for employing PLCs to improve PCK and the effectiveness of Science teaching and learning among teachers. Developers of Science curricula for the middle school can benefit from this study by identifying the dimensions and requirements of the TIMSS and the necessary PCK. In addition, the current study represents a practical guide for building PCL based on TIMSS requirements. It helps the developers of Science teachers' professional development programs in introducing programs to develop PCK in various Science topics.

\subsection{Limitations}

Subjective limits: this study is limited to PLC in the light of TIMSS, including seminars, action research and peer training. It also covers PCK and its five aspects, i.e. scientific content knowledge, curriculum knowledge, educational purposes knowledge, teaching practices knowledge, and educational context knowledge (Hashweh, 2005).

Spatial limits: Public and private middle schools for girls in Riyadh, Saudi Arabia.

Temporal limits: The study was applied in the academic year 2018/2019.

\subsection{Terms}

Effectiveness: Shehata and Najjar (2003) defines effectiveness as the impact extent that can be caused by the experimental intervention as an independent variable on one of the dependent variables.

The researchers procedurally define it as the impact extent caused by TIMSS requirementsbased PLC, as an independent variable, on the development of PCK among female Science teachers of middle school using a PCK test and an observation card.

Professional learning communities (PLCS): a group of teachers involved in reflective dialogue on of their teaching practices and collaborative learning to promote their efficiency and professional development (Toole \& Louis, 2003).

The researchers procedurally defines PLCs as a group of Science teachers of middle school get together to critically discuss their teaching practices in a reflective, cooperative and comprehensive manner. They interact with each other and with the surroundings to develop their PCK in the light of the dimensions of the TIMSS.

Trends in International Math and Science Study (TIMSS): a series of international assessments of student achievement in Math and Science in countries around the world. It aims at identifying the similarities and differences of the educational systems of these countries in order to improve the process of teaching and learning. It is implemented under supervision of the International Association for the Evaluation of Educational Achievement (IEA).

Pedagogical Content Knowledge (PCK): teachers' knowledge of the structure of TIMSS in terms of its main dimensions, i.e. content, cognitive processes, and scientific reflection to facilitate students' learning and comprehension of the content by using illustrations, clarifications, dialogue, examples, and presentations. The researchers prepared a PCK scale and a classroom observation card to measure PCK among Science teachers. 


\section{Conceptual Framework}

\subsection{Professional Learning Communities (PLCs)}

Educational literature has demonstrated that PLCs are an effective technique of teacher professional development. The school is perceived as a high-quality learning institution for all of its employees. Besides, PLCs seek to face the challenges that hinder the effectiveness of the school. Sergiovanni (1994) defines learning community as a group of individuals who interact personally or electronically and associate with each other to answer questions or solve problems or address common issues. The community members define a set of specific standards and procedures to ensure interaction, collaboration, and mutual trust as well as determination to hard work and focus on results.

DuFour, DuFour, Eacker, Many, \& Mattos (2016, p. 12) agree that the fundamental structure of PLC is "the collaborative teams of educators whose members work interdependently to achieve common goals for which members are mutually accountable. These common goals are directly linked to the purpose of learning for all".

The aim of PLC is to create a continuous schooling environment that supports and encourages learning among educators based on mutual trust and collaborative work (DuFour et al., 2016). It is an effective tool of professional development since it aims to develop a teamwork environment characterized by open communication and participation in decision-making and mutual understanding among educators (Provini, 2012).

PLCs lead to the development of social, academic, professional experiences and functioning among teachers and reaching high academic achievement ratios among students. That was asserted by Pratt (2014) who aimed to identify teachers' perspectives of PLCs regarding sharing best teaching practices, collective inquiry, and learning cooperation and interaction. It concluded that PLCs result in developing best teaching practices among teachers. It recommended the necessity of activating PLC and cooperative learning to disseminate successful teaching practices among teachers, especially in schools and districts in rural areas.

Stoll, Bolam, Mcmahon, Wallace, and Thomas (2006) counted the derives of building PLC within schools, including unfolding work experiences and effective practices through sharing experiences and ideas and thus affording opportunities for effective and rapid professional growth. Furthermore, PLC depends on ongoing research and reflection, which allow generating innovative ideas, providing immediate feedback, and affording supportive environment for all. Another significant benefit of PLC is the focus on leadership skills among educators by boosting role exchange, responsibility sharing and authority delegation, making a space for generating suggestions and solutions for problems. As reported by Fulton and Britton (2011), a school becomes effective by including teachers who have the leadership and support to create a learning culture that leads to higher academic achievements and abilities among learners. PLC creates a positive environment in schools not only for educators, but also for parents, students, and the local community (Stoll et al., 2006). It enhances professional growth, initiative, and innovation (Fulton \& Britton, 2011). According to DuFour, DuFour, \& Eaker (2008), the structure of high functioning PLC is characterized by a constant focus on student learning, collaborative culture and collective effort to support student learning, and focus on results to improve practices and ensure continuous development. Critical reflection within PLC enables a deep conceptual and practical changes as it involves an ongoing sharing of new ideas, reevaluation of the existing practices, giving-up long holding beliefs, and learning of new techniques (Feldman \& Fataar, 2014). PLC schools have to provide teachers with the necessary time for collective reflection and focused activities that lead to positive results (Lalor \& Abawi, 2014). 


\subsection{Pedagogical Content Knowledge (PCK)}

According to Shulman (1987), PCK is fundamental for educators and it involves knowledge of the content area and knowledge of the methods of presenting and facilitating it. PCK has a significant importance because it represents the maxims of "content-specific" knowledge and "general teaching principles" that "guide the practices of able teachers", including the practices of conceptual organization, inquiry, and adaptation (Shulman, 1987, p. 11). Shulman (1986) defines PCK as the teacher's use of the most useful forms of representation of ideas, illustrations, examples, explanations, and demonstrations to make the subject comprehensible to learners. It involves understanding of what makes a given lesson or topic difficult for students by identifying their perceptions and previous experiences about that topic.

Hashweh (2005) defines PCK as a set of knowledge or units composed of specific and personal Teacher Pedagogical Constructions (TPC) developed through the teacher's re-learning of particular subjects.

Shulman (1987, p. 8) discusses seven types of PCK, comprising "content knowledge, general pedagogical knowledge, curriculum knowledge, pedagogical content knowledge, knowledge of learners and their characteristics, and knowledge of the educational context, purposes, and objectives”.

Ball and Hill (2008) illustrates the knowledge embedded in PCK, as follows:

- Content knowledge or subject matter knowledge: it refers to teacher understanding of the structure of the educational material, including the basic concepts and generalizations of the subject area, and connections between these concepts and generalizations.

- General pedagogical knowledge: it represents the basic principles that underpin the process of teaching implementation, such as classroom management, teaching skills, learning time, waiting time, and the principles of individual and group interaction within the classroom.

- Curriculum knowledge: it indicates teacher knowledge of the curriculum and its basic elements, underpin theories, methods of evaluation, arrangement of experiences and activities, in addition to lesson planning, examination preparation, and teaching materials and aids employment.

- Pedagogical content knowledge: It includes the content-specific knowledge that enables the teacher to teach in real classroom situations. Accordingly, it is an amalgam of content and pedagogy besides an understanding of content organization and learning difficulties.

- Knowledge of learners and their characteristics: It means identifying learners' interests, educational needs, individual differences, previous experiences and concepts, alternative concepts, and misapplication of knowledge.

- Knowledge of educational context: It is related to classroom management, school knowledge, and respect for cultural and social diversities among students.

- Knowledge of educational purposes and values: it includes knowledge of the philosophical and historical grounds of education as well as the professional ethics of teaching.

The current study is limited to only five elements of PCK; namely, content knowledge, curriculum knowledge, educational purposes knowledge, teaching practices knowledge, and educational context knowledge.

\subsection{Trends in International Mathematics and Science Studies (TIMSS)}

International assessments of education, including the TIMSS, have emerged in the nineties of the twentieth century. TIMSS is a global assessment of Math and Science education, held regularly every four years. It aims to identify the effectiveness of the utilized curriculum, teaching and evaluation methods, and leaning resources to improve Math and Science teaching and learning. IEA monitors the process of its preparation and application in the participating countries (Al-Hussan, 
2015). It measures the differences among the educational systems in a number of countries around the world. This comparison aims to the development of the teaching and learning processes and the improvement of the involved educational materials. Math and Science tests are conducted simultaneously among fourth and eighth grades in the participating countries (Al-Fahidi, 2014). The First International Mathematics Study (FIMS) was held in 1964, while the assessment of student performance in Science, among six other subjects, begun in 1970 and 1971 (Al-Gharib, Al-Sadiq, \& Shaier 2012). However, the first TIMSS was conducted back in 1995.

According to Mullis and Martin (2013), and Abdul Salam, Qurany, and Abu El-Ezz (2007), TIMSS is of great importance since it affords valuable data to the participating countries which enables them to evaluate and follow up on Mathematics and Science education. In addition, it enables following-up the relative effects of teaching and learning in the fourth grade and benchmarking them in the eighth grade. It thus helps identify the best teaching and learning practices and educational policies that lead to the highest student achievement by benchmarking student results in many countries around the world.

\subsection{TIMSS requirements}

According to Mullis and Martin (2017), and Al-Hussan (2015), TIMSS 2019 framework for Science assessment includes two dimensions:

Content dimension: It specifies the main content areas of Science to be assessed at the fourth and eighth grades. These areas are represented in the tests according to specific relative weights. The eighth grade is evaluated in the context of four main areas with specific percentages, and these areas are as follows: Biology and its ratio (35\%), chemistry with a percentage $(20 \%)$, physics with a percentage $(25 \%)$, Earth Sciences and with a percentage $(20 \%)$.

Cognitive dimension: it describes the thinking processes students are expected to engage in when encountering the Science and Math items developed for TIMSS 2019, according to specific relative weights. The cognitive dimension has three levels of thinking that include knowing, applying, and reasoning.

\subsection{Science practices}

The framework for TIMSS 2019 describes five practices of Science investigation, including "asking questions based on observations, generating evidence, working with data, answering the research question, and making an argument from evidence" (Mullis \& Martin, 2017, p. 54). The current study focuses on the development of PCK based on TIMSS requirements among Science teachers of middle school. The framework for TIMSS 2019 (Mullis \& Martin, 2017) was utilized to set activities and problems introduced for teachers participating in a PLC. The researchers have benefited from a number of relevant previous studies, such as Sulaihem (2018) and models of TIMSS tests in the years (2003-2015) when Saudi Arabia participated. We also benefited from teacher questionnaires, educational context scale, school scale, and family questionnaire available on the website of the IEA to list the teaching knowledge required for Science teachers in the light of TIMSS requirements.

\section{Method \& Methodology}

To achieve the objectives of the current study, the quasi-experimental approach and the design of one group pre- and post-test were employed. The study instrument, PCK scale, was applied before and after the sample's participation in a PLC based on TIMSS requirements. The PCK scale was applied to measure the impact of the independent variable, TIMSS requirements-based PLC, on the dependent variable, Science teacher PCK. 


\subsection{Sampling}

The study population comprised female Science teachers of public and private middle schools in Riyadh, Saudi Arabia, who are on work during the second semester of the academic year 2018/2019. Cluster random sampling was employed and the study sample consisted of (20) Science teachers from six middle schools in Riyadh.

\subsection{Instrument}

To study the effectiveness of a PLC based on the TIMSS requirements in the development of PCK among Science teachers of the middle school, the researchers prepared a TIMSS requirements-based PLC. We also utilized the content of heat transfer and electrical circuits to prepare a PCK test. For data collection, focus sessions and self-reflection sessions were applied.

\subsection{Heat transfer and electrical circuits PCK scale}

The scale aimed at measuring PCK of heat transfer and electrical circuits among Science teachers of middle school based on the model developed by Hashweh (2005). The researchers also reviewed the relevant literature, including Miqdadi and Al-Omari (2014), Awad and El-Ramhy (2014), Hashweh (2013), and Al-Ramahi (2011). The initial form of the scale consisted of two parts. The first part measures scientific content knowledge and consists of seven multiple-choice questions and nineteen essay questions about the two topics of heat transfer and electrical circuits. The questions are formulated according to TIMSS cognitive dimension, i.e. knowing, applying, and reasoning. The correct answer for each question scores one, and the wrong answer scores zero.

The second part consists of nineteen multiple-choice and essay questions with scores ranged from ( 1 to 4). It measures four domains: purposes knowledge, curriculum knowledge, teaching practices knowledge, and educational context knowledge. Rubrics with a set of levels were prepared to assess participants' responses to this part of the scale.

\subsection{Scale validity}

\subsubsection{Face validity:}

The initial form of the scale was submitted to a panel of (15) experts (professors, associate professors, and assistant professors of Science curricula and methods of teaching) to evaluate the wording of the questions and its appropriateness to measure the PCK of heat transfer and electrical circuits. The experts' views were considered and specific items were modified.

Construct validity: the scale was applied to a pilot sample of (32) female Science teachers of middle school. To verify the validity of the scale questions, Pearson correlation coefficient between the question score and its domain total score was calculated. The calculated correlation coefficients were statistically significant at the level of (0.01) or (0.05), indicating the validity of all the scale questions.

Table 1: Correlation coefficients for the questions of the PCK scale $(\mathrm{N}=32)$

\begin{tabular}{|l|c|c|}
\hline Domain & Question & Correlation coefficient $^{(1)}$ \\
\hline \multirow{4}{*}{ Scientific content knowledge } & $\mathrm{Q}_{1}$ & $0.35^{*}$ \\
\cline { 2 - 3 } & $\mathrm{Q}_{4}$ & $0.53^{* *}$ \\
\cline { 2 - 3 } & $\mathrm{Q}_{5}$ & $0.49^{* *}$ \\
\cline { 2 - 3 } & $\mathrm{Q}$ & $0.42^{*}$ \\
\cline { 2 - 3 } & $\mathrm{Q}_{7}$ & $0.46^{* *}$ \\
\hline
\end{tabular}




\begin{tabular}{|c|c|c|}
\hline Domain & Question & Correlation coefficient $^{(1)}$ \\
\hline & Q8a & $0.58^{* *}$ \\
\hline & Q8b & $0.64^{* *}$ \\
\hline & Q8 c & $0.42^{*}$ \\
\hline & Q8d & $0.66^{* *}$ \\
\hline & Q9 & $0.61^{* *}$ \\
\hline & Q1ob & $0.52^{* *}$ \\
\hline & Q11 & $0.56^{* *}$ \\
\hline & Q12a & $0.44^{*}$ \\
\hline & Q12b & $0.64^{* *}$ \\
\hline & Q13 & $0.55^{* *}$ \\
\hline & Q14a & $0.54^{* *}$ \\
\hline & Q14b & $0.44^{*}$ \\
\hline & Q15a & $0.71^{* *}$ \\
\hline & Q15b & $0.58^{* *}$ \\
\hline & Q16 & $0.69^{\star *}$ \\
\hline & Q17a & $0.64^{* *}$ \\
\hline & Q17b & $0.62^{* *}$ \\
\hline & Q17c & $0.39^{*}$ \\
\hline \multirow[t]{5}{*}{ Purposes knowledge } & Q1 & $0.46^{* *}$ \\
\hline & Q2 & $0.48^{* *}$ \\
\hline & Q3 & $0.74^{* *}$ \\
\hline & $\mathrm{Q}_{4}$ & $0.78^{* *}$ \\
\hline & Q5 & $0.57^{* *}$ \\
\hline \multirow[t]{4}{*}{ Curriculum knowledge } & Q9 & $0.39^{*}$ \\
\hline & Q11 & $0.43^{*}$ \\
\hline & Q12 & $0.72^{* *}$ \\
\hline & Q13 & $0.68^{* *}$ \\
\hline \multirow[t]{6}{*}{ Teaching practices knowledge } & Q6 & $0.35^{*}$ \\
\hline & Q7 & $0.56^{* *}$ \\
\hline & Q8 & $0.63^{* *}$ \\
\hline & Q14 & $0.57^{* *}$ \\
\hline & Q15 & $0.66^{* *}$ \\
\hline & Q16 & $0.67^{* *}$ \\
\hline \multirow[t]{3}{*}{ Educational context knowledge } & Q17 & $0.51^{* *}$ \\
\hline & Q18 & $0.81^{* *}$ \\
\hline & Q19 & $0.83^{* *}$ \\
\hline
\end{tabular}

(1) Correlation coefficient between the question and its domain after omitting the question score from the domain total score.

* significant at the level of (0.05).

** significant at the level of (o.o1).

\subsubsection{Construct validity}

The validity of the scale domains was verified by calculating the coefficient of correlation between each domain score and the scale total score. The obtained correlation coefficients were statistically significant at the significance level of (o.o1) and ranged between (0.63-0.93), indicating the validity of the domains to measure the PCK of heat transfer and electrical circuits among participants.

\subsection{Scale reliability}

To verify the PCK scale reliability, it was applied to a pilot sample of (32) female Science teachers of middle school. Cronbach's alpha coefficient for each domain and Pearson correlation coefficient 
between the question score and its domain total score were calculated. The calculated correlation coefficients were statistically significant at the level of (0.01) or (0.05), indicating the internal consistency and reliability of all the scale questions.

Tablez: Correlation coefficients for the reliability of the PCK scale questions $(\mathrm{N}=32)$

\begin{tabular}{|c|c|c|c|}
\hline Domain & Question & Cronbach's alpha & Correlation coefficient $^{(1)}$ \\
\hline \multirow[t]{4}{*}{ Scientific content knowledge } & $\mathrm{Q}_{1}$ & 0.905 & $0.38^{*}$ \\
\hline & $\mathrm{Q}_{4}$ & 0.901 & $0.58^{* *}$ \\
\hline & Q5 & 0.902 & $0.55^{* *}$ \\
\hline & Q6 & 0.904 & $0.48^{* *}$ \\
\hline \multirow{19}{*}{$\begin{array}{l}\text { Total Cronbach's alpha for the domain } \\
0.905\end{array}$} & Q7 & 0.903 & $0.52^{* *}$ \\
\hline & Q8a & 0.900 & $0.63^{* *}$ \\
\hline & Q8b & 0.899 & $0.68^{* *}$ \\
\hline & Q8 c & 0.904 & $0.49^{* *}$ \\
\hline & Q8d & 0.899 & $0.70^{* *}$ \\
\hline & Q9 & 0.899 & $0.65^{* *}$ \\
\hline & Q1ob & 0.901 & $0.57^{* *}$ \\
\hline & Q11 & 0.900 & $0.62^{* *}$ \\
\hline & Q12a & 0.903 & $0.49^{* *}$ \\
\hline & Q12b & 0.899 & $0.69^{* *}$ \\
\hline & Q13 & 0.901 & $0.60^{* *}$ \\
\hline & Q14a & 0.901 & $0.60^{* *}$ \\
\hline & Q14b & 0.903 & $0.51^{* *}$ \\
\hline & Q15a & 0.897 & $0.75^{* *}$ \\
\hline & Q15b & 0.900 & $0.63^{* *}$ \\
\hline & Q16 & 0.897 & $0.73^{* *}$ \\
\hline & Q17a & 0.899 & $0.69^{* *}$ \\
\hline & Q17b & 0.899 & $0.66^{* *}$ \\
\hline & Q17C & 0.904 & $0.45^{* *}$ \\
\hline \multirow{5}{*}{$\begin{array}{l}\text { Purposes knowledge } \\
\text { Total Cronbach's alpha for the domain } \\
\text { o.814 }\end{array}$} & Q1 & 0.814 & $0.65^{* *}$ \\
\hline & Q2 & 0.811 & $0.65^{* *}$ \\
\hline & Q3 & 0.734 & $0.85^{* *}$ \\
\hline & $\mathrm{Q}_{4}$ & 0.720 & $0.88^{* *}$ \\
\hline & Q5 & 0.787 & $0.73^{* *}$ \\
\hline \multirow[t]{2}{*}{ Curriculum knowledge } & Q9 & 0.750 & $0.67^{* *}$ \\
\hline & Q11 & 0.749 & $0.63^{* *}$ \\
\hline \multirow[t]{2}{*}{ Total Cronbach's alpha for the domain 0.750} & Q12 & 0.583 & $0.87^{* *}$ \\
\hline & Q13 & 0.607 & $0.85^{* *}$ \\
\hline \multirow{6}{*}{$\begin{array}{l}\text { Teaching practices knowledge } \\
\text { Total Cronbach's alpha for the domain } \\
\text { o.776 }\end{array}$} & Q6 & 0.776 & $0.35^{*}$ \\
\hline & Q7 & 0.739 & $0.69^{* *}$ \\
\hline & Q8 & 0.712 & $0.78^{* *}$ \\
\hline & Q14 & 0.729 & $0.73^{* *}$ \\
\hline & Q15 & 0.707 & $0.79^{* *}$ \\
\hline & Q16 & 0.703 & $0.80^{* *}$ \\
\hline \multirow{3}{*}{$\begin{array}{l}\text { Educational context knowledge } \\
\text { Total Cronbach's alpha for the domain o.840 }\end{array}$} & Q17 & 0.840 & $0.74^{* *}$ \\
\hline & Q18 & 0.666 & $0.92^{* *}$ \\
\hline & Q19 & 0.644 & $0.93^{* *}$ \\
\hline
\end{tabular}

(1) Correlation coefficient between the question and its domain while including the question score in the domain total score.

* significant at the level of (0.05).

** significant at the level of (o.o1).

The total PCK scale reliability was calculated by Cronbach's alpha and Spearman-Brown split-half. 
The obtained coefficients were high and ranged between (0.750-0.905), demonstrating the reliability of the scale and its domains.

\subsection{Qualitative analysis tools}

To identify the effectiveness of a PLC based on the TIMSS requirements in the development of PCK among Science teachers of the middle school, the researchers prepared focus sessions and selfreflection sessions, as informal tools. They were prepared according to the PCK list of TIMSS requirements, as follows:

Focus sessions:

Focus sessions are face-to-face discussions applied during the PLC and the topics were selected in the light of the TIMSS requirements. The PLC participants were engaged in group discussion and investigation as well as WhatsApp group sessions. The dialogues in these sessions were utilized in the interpretation of the study results.

Self-reflection sessions:

The participating teacher thinks of her teaching practices to identify points of strength and weakness by following some basic steps (Irfan \& Essam, 2014). The researchers helped the participants to put down their investigations by applying the steps of self-reflection. They were asked to reflect on the classroom difficulties they faced whilst raising TIMSS questions from various knowledge levels, and on how students improved in dealing with these questions. Participants' written reflections were utilized in the interpretation of the study results.

\subsection{Statistical analysis methods}

SPSS software was utilized to calculate the following

1. Pearson correlation coefficient to verify of the internal consistency of the PCK scale;

2. Cronbach's Alpha to calculate the consistency of the PCK scale;

3. Coefficients of easy, difficulty, and discrimination to analyze the item of the PCK scale;

4. Paired Samples T-test to study the differences between pre and post applications among the experimental group;

5. Eta Square to calculate the effect size of a TIMSS requirements-based PLC on the development of PCK among Science teachers of the middle school in the experimental group.

\section{Results}

To test the study hypothesis that: There are statistically significant differences at the significance level (o.o1) between the mean scores of the experimental group of Science teachers of middle school in the pre and post PCK test, in favor of the post-test mean scores, Paired Samples T Test and Eta Squared $\eta^{2}$ were utilized to calculate the effect size of TIMSS requirements-based PLC on the development of PCK among Science teachers of the middle school. We utilized the following equation of Eta Squared effect size $\eta^{2}$, T values and degrees of freedom:

$$
\eta^{2}=\frac{t^{2}}{t^{2}+d f}
$$

Where $\eta^{2}$ is Eta Squared or the effect size, $t^{2}$ is the T-test value squared, and $d f$ is the degrees of freedom equal to $(\mathrm{N}-1)$, as $\mathrm{N}$ is the number of the experimental group teachers (Hassan, 2016).

In addition, Modified Blake's Gain Ratio is calculated by the following formula:

$$
M G_{\text {Blake }}=\frac{M_{2}-M_{1}}{P-M_{1}}+\frac{M_{2}-M_{1}}{P}
$$




$$
M G_{\text {Blake }}=\frac{M_{2}-M_{1}}{P-M_{1}}+\frac{M_{2}-M_{1}}{P}
$$

Where $M G_{\text {Blake }}$ is the Modified Blake's Gain Ratio, $M_{1}$ is pre-measurement mean, $M_{2}$ is the postmeasurement mean, and $P$ is the possible test score (likelihood).

The following table shows the obtained results.

Table 3: Eta squared, modified Blake's Gain Ratio, T-test of the mean scores in the pre and post application of the PCK scale

\begin{tabular}{|l|c|c|c|c|c|c|c|}
\hline \multirow{2}{*}{ Tool } & \multicolumn{2}{|c|}{ Pretest } & \multicolumn{2}{c|}{ Posttest } & \multirow{2}{*}{ T value } & \multirow{2}{*}{$\eta^{2}$} & \multirow{2}{*}{ MG $G_{\text {Blake }}$} \\
\cline { 2 - 5 } & Mean & SD & Mean & SD & & \multirow{2}{*}{1.15} \\
\hline PCK scale & 50.83 & 13.63 & 85.45 & 6.49 & $13.37^{* *}$ & 0.9039 & 1.15 \\
\hline
\end{tabular}

** Statistically significant at the significance level of (o.o1).

Table (3) demonstrates that there are statistically significant differences at the significance level (o.o1) between the mean scores of the experimental group in the pre and post PCK test, in favor of the posttest mean scores. The value of Eta squared of the PCK scale equaled to (o.9093), indicating that the independent variable TIMSS requirements-based PLC has a very big effect size on the development of the participants' total score in the scale of the PCK of heat transfer and electrical circuits. Further, Eta squared pointed out that the independent variable has (90.39\%) of variation in the total score of PCK scale, indicating a very high variation explained by the independent variable among the experimental group participants.

The value Eta squared for the classroom observation card, utilized to measure PCK among middle school Science teachers, equaled to (o.9738), i.e. the independent variable has a very big effect size on the development of PCK among participants.

The modified Blake's Gain values for the test got (1.15) and it is close to (1.2), the value which was proposed by Black to assert a program effectiveness. It shows that independent variable is effective in the development of PCK among participants. Table (4) illustrates the results of T-test, Eta squared, and modified Blake's Gain Ratio for each domain of the PCK scale, as follows:

Table 4: Eta squared, modified Blake's Gain Ratio, T-test of the mean scores in the pre and post-test for each domain of the PCK scale

\begin{tabular}{|l|c|c|c|c|c|c|c|}
\hline \multirow{2}{*}{ Domain } & \multicolumn{2}{|c|}{ Pretest } & \multicolumn{2}{|c|}{ Posttest } & \multirow{2}{*}{ T value } & \multirow{2}{*}{$\eta^{2}$} & \multirow{2}{*}{ MG $G_{\text {Blake }}$} \\
\cline { 2 - 8 } & Mean & SD & Mean & SD & & & \\
\hline Scientific content knowledge & 11.38 & 3.30 & 20.35 & 1.80 & $10.61^{* *}$ & 0.8557 & 1.16 \\
\hline Educational purposes knowledge & 10.80 & 3.19 & 18.00 & 2.29 & $10.37^{* *}$ & 0.8498 & 1.16 \\
\hline Curriculum knowledge & 8.15 & 3.15 & 13.90 & 2.45 & $7.33^{* *}$ & 0.7388 & 1.09 \\
\hline Teaching practices knowledge & 14.80 & 5.81 & $\mathbf{2 2 . 6 0}$ & 1.54 & $6.81^{* *}$ & 0.7091 & 1.17 \\
\hline Educational context knowledge & 5.70 & $\mathbf{2 . 6 2}$ & 10.60 & 0.88 & $7.80^{* *}$ & 0.7622 & 1.19 \\
\hline
\end{tabular}

** Statistically significant at the significance level of (o.o1).

Table (4) demonstrates that there are statistically significant differences at the significance level (o.o1) between the mean scores of the experimental group of Science teachers of middle school in the pre and post PCK test, in favor of the post-test mean scores in the five PCK domains.

The Eta squared value for the independent variable, TIMSS requirements-based PLC, has a very big effect size on the development of the five domains of the PCK among participants. Further, Eta squared pointed out that the independent variable has $(85.57 \%, 84.98 \%, 73.88 \%, 70.91 \%, 76.22 \%)$ of variation in the five domains of the PCK scale, indicating a very high variation explained by the independent variable among the experimental group participants.

The modified Blake's Gain values for the test were close to (1.2), the value which was proposed 
by Black to assert a program effectiveness. It shows that independent variable is effective in the development of the domains of PCK among participants.

\section{Discussion}

The fundamental base of PLC is the social structural theory that approaches learning as a knowledge acquisition process affected by teachers' interaction and engagement in a social environment that encourages constructive participation and dialogue that lead to the development of their knowledge and performance. Applying a PLC based on the requirements of the TIMSS works as professional development program for the participating science teachers. As mentioned by Provini (2012), PLCs represent an entry to ongoing professional development of teachers' knowledge and abilities.

The PLC purposed in this study is based on the requirements of the TIMSS assessment, thus it included various components, reflective practices, functioning activities and tasks, peer visits, action research, and workshops. As a result, it contributed to opening the doors of scientific knowledge relevant to the domains of TIMSS before the participating teachers. They became more informed by the dimensions of the TIMSS, specifically content knowledge and cognitive processes knowledge. They gained knowledge about the international educational purposes and objectives adopted by the countries participating in the TIMSS. They also identified the best strategies employed by global educational systems for teaching Science subjects. Furthermore, they became familiar with the educational context of the TIMSS and its impact on student learning and achievement. Accordingly, the TIMSS requirements-based PLC led to the improvement of PCK among the participating Science teachers. It afforded equal opportunities of knowledge for all the participants to gain information about the PCK required for meeting TIMSS requirements. Their participations in the prepared PLC resulted in increasing their knowledge of the relevant five domains, i.e. scientific content knowledge, educational purposes knowledge, curriculum knowledge, teaching practices knowledge, and educational context knowledge.

In the PLC focus and self-reflection sessions, the teachers discussed the scientific content and concepts of the topics included in the test. They raised varied questions about some concepts that seem to be difficult for their students. They sought to gain a deep understanding of these concepts and to learn about the best methods for representing them properly for students. In addition, they searched the Internet for the topics in hand and discussed their scientific readings and conclusions with their peers. The teachers also handled the relation between student levels of cognitive thinking and learning objectives and the best ways for improving student cognitive thinking abilities. They also focused on how to train students on scientific application and reasoning and the best teaching and evaluation practices that proved effective throughout their experiences. On the WhatsApp group, important issues emerged, such as the vertical and horizontal articulation of scientific concepts and knowledge. Later on, in a face-to-face focus session, the same topic was revisited and they talked about how they could employ vertical and horizontal articulation of scientific concepts in the curriculum taught.

Unsurprisingly, the teachers had already a great deal of PCK accumulated through the years of their experience in the teaching field. Self-reflections demonstrated their awareness of the importance of building their knowledge of the new content included in curriculum taught. Other focus sessions covered teachers' knowledge of the educational context and its role the process of student learning. It was noted that the participants had a low level of the educational context knowledge. Accordingly, the researchers directed the debate to the importance of employing the educational context in the process of student leaning, such as the participation of parents in Science classes. The teachers eventually got it and they began to narrate various ways of employing the educational context.

In accordance with the current study results, the reports conducted by the IEA illustrated that professional development centered on content increases teachers' engagement and motivation to attend workshops, conferences and seminars in the field of Science education and thus improves 
their effectiveness and expands their knowledge (Mullis \& Martin, 2013; Woolway, Msimanga, \& Lelliott 2019). It agrees also with the results of (Owen, 2014; Peppers, 2015; Pratt, 2014; Riveros, Newton, \& Burgess, 2012) concluding that there is a correlation between PLCs and teacher professional knowledge improvement. As emphasized by Mesa and Pringle (2019), middle school Science teachers' participation in PLC improves their teaching practices and increased student learning. Blitz (2013) also concluded that applying PLCs had short-term outcomes and shifted teachers' knowledge, beliefs and attitudes.

\section{Conclusion}

PLCs seek to achieve an on-going and constant professional development of teachers' beliefs and attitudes by refining the teaching and learning practices and applying certain strategies proper for specific educational situations. In PLC, professional integration among educators is fulfilled by creating an environment based on support and cooperation. Ultimately, PLC results in deeply profound developments in educators' teaching practices and knowledge by shifting their assumptions, beliefs, values, expectations, and habits. According to the current study results, PLC proved effective in developing a positive attitude among teachers. It was evident in their willingness to join the proposed PLC, the focus sessions, and self-reflection sessions. More important was the witnessed gradual improvements in their classroom practices and reflections. As they asserted in the held discussions, they benefited most from joining the PLC and gained a wealth of experiences. Furthermore, they expressed the necessity of activating PLCs continuously in various schools and educational districts. Similarly, a positive attitude towards TIMSS was formed among teachers who became more convinced of the importance of the international assessments. At the beginning of the PLC, they seemed unsure about the significance of such assessments. After identifying the philosophy and objectives behind the TIMSS, they developed a clearer conception of it and spelled their desire to apply its domains to their students. As they mentioned, classroom interaction increased among students and their learning results improved. The results also demonstrated the effectiveness of PLCs in satisfying teachers' professional training needs, such as designing reflective activities, composing good descriptive questions appropriate to TIMSS learning levels and cognitive processes. The teachers successfully designed reflective activities and regularly presented them to their students on a weekly basis. It confirms that the PLC helps meet adults' learning needs and increase their motivation that agree with of the principles of adult learning theory. As observed in the self-reflections, the teachers' ability to investigate their teaching and classroom practices remarkably evolved. They became more able to identify their weakness points that need development or change. They also began to propose plans and solutions to the identified classroom problems. Collective and individual reflections proved a shift in their views and practices. They had more faith in their abilities to change their everyday classroom practices by reflection, investigation, and collective learning. Meeting the requirements of the TIMSS by reformulating the questions presented to students and focus on learning results became among their top priorities. In sum, the study results confirmed that teachers' integration in TIMSS requirements-based PLC is effective in the improvement of their PCK.

\section{Recommendations}

In the light of the study results, the researchers recommend the following:

Creating PLCs within schools and educational districts is highly recommended. Within these PLCs, Science teachers should be encouraged to share their successful experiences as well as the points of weakness of some practices they observed. It helps achieve the PLC goals of cooperative learning among educators by identifying the problem causes and searching for suitable solutions. Science teachers should be encouraged to be conscious of the importance of PCK and how to improve it. Professional developers are recommended to train educators on self-reflection and collaborative learning. Work groups within the PLCs need to focus on reflection, dialogue and inquiry. 
Participation in regular discussions helps mitigate the burden of teaching problems among teachers and reach real solutions that lead to fundamental changes in knowledge and practices. Finally, following-up the application of the PLC suggestion and its integration in everyday classroom practices is of great importance for achieving the desired effective implications.

\section{References}

Abdul Salam, M., Qurany, Z., \& Abu El-Ezz, A. (2007). A model for Science curriculum development for basic education in the light of TIMSS requirements. A paper presented to the 11th Scientific Conference titled "Scientific Education ... Where To?" held in The Egyptian Association for Scientific Education, Ismailia, 2931/ 7/2007, 141-231.

Al-Fahidi, H. (2014). Evaluation of the content of Science curricula for basic education in Saudi Arabia according to TIMSS requirements. Journal of Education, Al-Azhar University, 158(1), 589-648.

Al-Gharib, W., Al-Sadiq, M., \& Shaier, I. (2012). An evaluation of the questions of Science textbook and exams for basic education in the light of the TIMSS domains. Journal of Education College in Mansoura, 1(79), 519-557.

Al-Hussan, A. (2015). The extent of meeting the requirements of TIMSS 2015 the Science textbooks of the grades from first to the fourth in Saudi Arabia: An analytical study. Zarqa Journal for Research and Studies in Humanities, 15(1), 111-132.

Al-Ramahi, R. (2011). The effect of a training program on developing professional knowledge in Engineering among mathematics teachers for basic education and improving student achievement Palestine. (Unpublished PhD Diss.). University of Jordan, Jordan.

Awad, D., \& El-Ramhy, R. (2014). Exploring the effect of a training program on developing pedagogical content knowledge among Mathematics teachers of the tenth grade: A case study. (Unpublished MA thesis). Birzeit University, Birzeit.

Ball, D., \& Hill, H. (2009). The curious - and crucial - case of mathematical knowledge for teaching. Kappan, 91(2), 54-59.

Blitz, C. (2013). Can online learning communities achieve the goals of traditional professional learning communities? What the literature says. Regional Educational Laboratory mid-Atlantic. Retrieved from: https://files.eric.ed.gov/fulltext/ED544210.pdf

De Jong, O., Van Driel, J., \& Verloop, N. (2005). Pre-service teachers' pedagogical content knowledge of using particle models when teaching chemistry. Journal of Research in Science Teaching, 42, 947-964.

Dogan, S., Pringle, R., \& Mesa, J. (2016). The impacts of professional learning communities on science teachers' knowledge, practice and student learning: A review. Professional Development in Education, 42 (4), 569-588.

Drechsler, M., \& Driel, J. (2008). Experienced Teachers' Pedagogical Content Knowledge of Teaching Acid - base Chemistry. Research in Science Education, 38 (5), 611-631. https://doi.org/10.1007/s11165-007-9066-5

DuFour, R. (2004). What Is a "Professional Learning Community"? Educational Leadership, 61, 6-11.

DuFour, R., DuFour, R., \& Eaker, R. (2008). Revisiting professional learning communities at work: New insights for improving schools. Bloomington, IN: Solution Tree.

DuFour, R., DuFour, R., Eacker, R., Many, T., \& Mattos, M. (2016). Learning by doing: A handbook for professional learning communities at work. $3^{\text {rd }}$ ed. Solution Tree Press, USA.

Feldman, J., \& Fataar, A. (2014). Conceptualizing the setting up of a professional learning community for teachers' pedagogical learning. South African Journal of Higher Education, 28(1), 1525-1539.

Fulton, K., \& Britton, T. (2011). STEM teachers in professional learning communities: From good teachers to great teachers. Washington, DC: National Commission on Teaching and America's Future.

Ghoneim, S., Abd, E. and Ayyash, A. (2016). Forms of pedagogical content knowledge among Science and Mathematics teachers of the third grade in Jordan and its effect on their educational beliefs. Educational Sciences Studies, 3(4), 1463-1481.

Hashweh, M. (2005). Teacher pedagogical constructions: A reconfiguration of pedagogical content knowledge. Teachers and Teaching: theory and practice. 11. 273-292.

Hashweh, M. (2013). Pedagogical content knowledge: Twenty-five years later, Emerald Group Publishing Limited, 19, $115-140$.

Hassan, E. (2016). Psychological and educational statistics: SPSS software applications. Cairo: Dar Al-Fikr Al-Arabi.

Hultén, M. \& Björkholm, E. (2015). Epistemic habits: Primary school teachers' development of pedagogical content knowledge (PCK) in a design-based research project. International Journal of Technology and Design Education, 26(3), 335-351. 
Hussein, B. (2014). The effect of academic and educational qualification on Science teachers' application of pedagogical content knowledge in their teaching .Arabic Studies in Education and Psychology, 1(46), 50-72.

Irfan, K., \& Essam, M. (2014). A program based on self-reflection for the development of the interactive research skills among students of the colleges of Education. Journal of Education, Al-Azhar University, 3(161), 107-155.

Kapyla, M., Heikkinen, J., \& Asunta, T. (2009). Influence of content knowledge on pedagogical content knowledge: The case of teaching photosynthesis and plant growth. International Journal of Science Education, 31(10), 1395-1415.

Lalor, B. \& Abawi, L. (2014). Professional learning communities enhancing teacher experiences in international schools. International Journal of Pedagogies and Learning, 9(1), 76-86.

Leclerc, M., Moreau, A., Dumouchel, C., \& Salla, F. (2012). Factors that promote progression in schools functioning as a professional learning community. International Journal of Education Policy and Leadership, 7(7), 1-14.

Lewis, E., Baker, D., Watts, N., \& Lang, M. (2014). A Profession Community activity for science teachers: How to incorporate instructional strategies into science lessons. Science Educator, 23(1), 1-9.

Melo-Niño, L., Cañada, F., \& Mellado, V. (2017). Initial characterization of Colombian high school Physics teachers' pedagogical content knowledge on electric fields. Research in Science Education, 47(1), $25-48$. Available at: https://doi-org.sdl.idm.oclc.org/10.1007/s11165-015-9488-4

Mesa, J. \& Pringle, R. (2019). Change from within: Middle school Science teachers leading professional learning communities. Middle School Journal, 50(5), 5-14. Available at: https://doiorg.sdl.idm.oclc.org/10.108o/o0940771.2019.1674767 .

Ministry of Education. (2019). TIMSS assessment and the pursuit of educational development. Retrieved from: https://www.moe.gov.sa/ar/news/Pages/te-214.aspx

Miqdadi, R., Al-Omari, W. (2014). Examining Mathematics and Science Teachers' Perceptions of their Pedagogical Content knowledge, Jordan Journal of Educational Sciences, 10(3), 383-394.

Mullis, I. \& Martin, M. (Eds.). (2013). Chestnut Hill M PIRLS International Study Center , Boston College.

Mullis, I. \& Martin, M. (Eds.). (2017). TIMSS 2019 Assessment Frameworks. Boston College, TIMSS \& PID International Study Center website. Retrieved from: http://timssandpirls.bc.edu/timss2019/frameworks/nternational-resule .

Owen, S. (2014). Teacher professional learning communities: Going beyond contrived collegiality toward challenging debate and collegial learning and professional growth. Australian Journal of Adult Learning, 54(2), 54-77.

Ozden, M. (2008). The effect of content knowledge on pedagogical content knowledge: The case of teaching phases of matters. Educational Sciences: Theory E Practice, 8(2), 633-645.

Peppers, G. (2015). Teachers' perceptions and implementation of professional learning communities in a large suburban high school. Nat Education Journal, 8 (1), 25-31.

Pratt, A. (2014). Teacher Perspectives of professional learning community teams with respect to their collective inquiries: A case study. Doctoral dissertation. Liberty University, US, Available at Poquest: http://search.Proquest.com.

Provini, C. (2012). Best practices for professional learning community. Education world.

Riveros, A., Newton, P., \& Burgess, D. (2012). A situated account of teacher agency and learning: critical reflections on professional learning communities. Canadian Journal of Education, 35 (1), 202-216.

Sergiovanni, T. (1994). Building community in schools. San Francisco: Jossey-Bass.

Shehata, H. and Najjar, Z. (2003). A glossary of educational and psychological terms. The Egyptian Lebanese House: Cairo.

Shulman, L. (1987). Knowledge and Teaching: Foundations of the New Reform. Harvard Education Review, 57(1), 121.

Shulman, L. (1986). Those who understand: Knowledge growth in teaching. Educational Researcher, 15 (2), 4-14.

Stoll, L., Bolam, R., Mcmahon, A., Wallace, M. \& Thomas, S. (2006). Professional learning communities: A review of the literature. Journal of Educational Change, 7(4), 221-258.

Sulaihem, H. (2018). A training program proposed in accordance with TIMSS requirements and its effectiveness in developing teaching skills for middle school Science teachers and student achievement. (Unpublished PhD Diss.). Imam Muhammad bin Saud University, Riyadh.

Thompson, J., Richards, J., Shim, S.-Y., Lohwasser, K., Von Esch, K. S., Chew, C., ... Morris, A. (2019). Launching networked PLCs: Footholds into creating and improving knowledge of ambitious and equitable teaching practices in an RPP. AERA Open, 5(3), 1-22.

Toole, J. \& Louis, K. (2003). The role of professional learning communities in international Education, in K. lethwood and p. Hollinger (eds) second international handbook of educational leadership and administration. Dordrecht: Kluwer. 
Voelkel, R. (2011). A Case Study of the Relationship between Collective Efficacy and Professional Leaming Communities. Doctoral dissertation, California State University, U.S. Available at ProQuest: http://search.proquest.com.

Wenger, E., McDermott, R. \& Snyder, W. (2002). Cultivating Communities of Practice: A Guide to Managing Knowledge. Boston: Harvard Business School Press.

Woolway, J., Msimanga, A., \& Lelliott, A. (2019). Continuous Collaborative Reflection Sessions in a Professional Learning Community: The Development of Grade 8 Natural Sciences Teachers' Reflective Practice. African Journal of Research in Mathematics, Science E Technology Education, 23(1), 1-13. 